\title{
Homogeneous liquid-liquid extraction of metal ions with non- fluorinated bis(2-ethylhexyl)phosphate ionic liquids having a lower critical solution temperature in combination with water
}

Received 00th January 20xx, Accepted 00th January 20xx

DOI: $10.1039 / \times 0 \times x 00000 x$
Daphne Depuydt, ${ }^{a}$ Liwang Liu, ${ }^{\mathrm{b}}$ Christ Glorieux, ${ }^{\mathrm{b}}$ Wim Dehaen, ${ }^{\mathrm{a}}$ and Koen Binnemans ${ }^{\mathrm{a}}$

www.rsc.org/

Ionic liquids with an ether-functionalised cation and the bis(2ethylhexyl)phosphate anion show thermomorphic behaviour in water, with a lower critical solution temperature. These ionic liquids are useful for homogeneous liquid-liquid extraction of first period (3d) transition metals.

Ionic liquids (ILS) are solvents that consist entirely of ions. ${ }^{1-3}$ They are distinguished from molten salts by their low melting temperature, arbitrarily set at $100{ }^{\circ} \mathrm{C}$. ILs are often considered as environmentally friendly alternatives for molecular solvents in solvent extraction since they have a negligible vapour pressure. ${ }^{4}$ The physical properties of ILs depend on their structure. Depending on its composition, an ionic liquid is miscible or immiscible with water, leading to a classification into hydrophilic and hydrophobic ionic liquids. Yet, this classification is ambiguous, since the miscibility of some ILs with water is strongly temperaturedependent. In upper critical solution temperature (UCST) systems, the solubility of the IL in water increases with increasing temperature and a homogeneous system is found above a certain point in the cloud point curve, namely above the upper critical solution temperature, the components are miscible in all concentrations. The opposite happens for the lower critical solution temperature (LCST) systems, in which the homogeneous phase is formed with a decrease of temperature. It has been reported that ionic liquids have temperature-dependent miscibility with different molecular solvents. ${ }^{5,6,7,8}$ Ohno and co-workers made seminal contributions to LCST phase changes in ionic liquids. ${ }^{9-16}$ They have prepared ionic liquids derived from amino acids that show LCSTtype phase changes with water. ${ }^{17} \mathrm{IL}$-water biphasic mixtures are of interest for the separation of molecules by solvent extraction. In 2006, we reported on the IL betainium bis(trifluoromethylsulfonyl) imide ([Hbet] $\left.\left[\mathrm{Tf}_{2} \mathrm{~N}\right]\right)$ which, mixed with water, shows an UCST at 55

\footnotetext{
${ }^{a}$ KU Leuven, Department of Chemistry, Celestijnenlaan 200F, P.O Box 2404, B3001 Heverlee (Belgium).E-mail: Koen.Binnemans@chem.kuleuven.be

${ }^{b}$ KU Leuven, Department of Physics and Astronomy, Celestijnenlaan 200D P.O Box 2416, B-3001 Heverlee (Belgium).
}

† Electronic Supplementary Information (ESI) available: Experimental details of synthesis and characterisation of ionic liquids, temperature dependence of transmitted intensity, ATR-FTIR, extraction details. See DOI: 10.1039/x0xx00000x
${ }^{\circ} \mathrm{C} .{ }^{18}$ It has been used in the homogeneous liquid-liquid extraction (HLLE) of metal ions. ${ }^{19-21}$ The binary mixture of choline bis(trifluoromethylsulfonyl)imide ([Chol] $\left.\left[\mathrm{Tf}_{2} \mathrm{~N}\right]\right)$ and water shows temperature-dependent phase behaviour with an upper critical solution temperature of $72{ }^{\circ} \mathrm{C}$ and has been used for the HLLE of $\mathrm{Nd}(\mathrm{III}) .{ }^{22}$ A series of ILs based on Girard's reagents have tunable thermomorphism of the UCST type and were used for HLLE of transition metals. ${ }^{23}$ In the literature, the LCST behaviour of both glycol ether-water mixtures, ${ }^{24}$ and functionalised polymers with glycol chains ${ }^{25}$ were described. The ionic liquid interpretation of the LCST phase behaviour can be comprehended based on the knowledge from polymer studies. Although Ohno and co-workers reported the HLLE of LCST ionic liquids for the extraction of proteins, ${ }^{26,27}$ the use of such a LCST system was, until now, never executed for the extraction of metal ions.

In this Communication, ionic liquids having the bis(2-ethylhexyl) phosphate as anion are presented that show lower critical solution temperature phase behaviour. A proof-of-principle extraction of first row transition metals by the ionic liquid $\left[\mathrm{P}_{444} \mathrm{E}_{3}\right][\mathrm{DEHP}]$ is the first example of homogeneous liquid-liquid extraction of metal ions with an LCST thermomorphic system. The designed ILs are depicted in Figure 1. The synthesis of the ether-functionalised ionic liquids was based on literature procedures. ${ }^{28}$ After tri- $n$ butylphosphine was reacted with a chloride oligo ethylene precursor, a metathesis reaction was performed in which the chloride anion of the ether-functionalised ILs was exchanged to the bis(2-ethylhexyl)phosphate (DEHP) (Experimental Section).

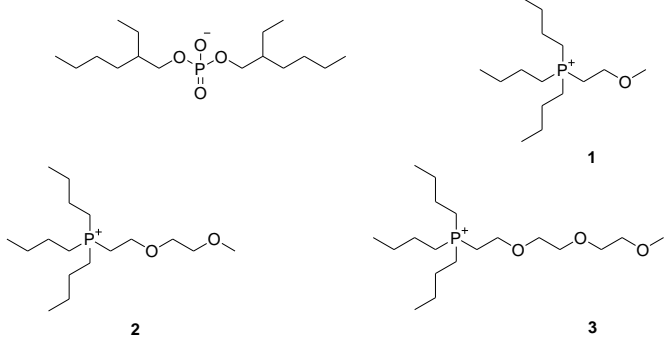

Figure 1. Structures of investigated ILs. Anion: bis(2-ethylhexyl)phosphate ([DEHP]) Cations: 1: tri- $n$-butyl-2-methoxyethylphosphonium $\left(\left[\mathrm{P}_{444} \mathrm{E}_{1}\right]^{+}\right), 2$ : $\operatorname{tri-} n$-butyl[2-(2methoxyethoxy)ethyl]phosphonium $\quad\left(\left[\mathrm{P}_{444} \mathrm{E}_{2}\right]^{+}\right), \quad 3: \quad$ tri- $n$-butyl- $\{2-[2-(2-$ methoxyethoxy)ethoxy]ethyl\}phosphonium $\left.\left[\mathrm{P}_{444} \mathrm{E}_{3}\right]^{+}\right)$. 
Table 1. Viscosity, water content and phase behaviour of ether-functionalised ILs.

\begin{tabular}{ccccc}
\hline Entry & & $\begin{array}{c}\text { Viscosity }(\mathrm{cP}) \\
\text { at } 50{ }^{\circ} \mathrm{C}\end{array}$ & $\begin{array}{c}\text { Water content } \\
(\mathrm{ppm})\end{array}$ & $\begin{array}{c}\text { Phase } \\
\text { behaviour } \\
\text { with water }\end{array}$ \\
\hline $1 \mathrm{a}$ & {$\left[\mathrm{P}_{444} \mathrm{E}_{1}\right] \mathrm{Cl}$} & 364 & n.d. $^{\mathrm{a}}$ & miscible $^{\mathrm{b}}$ \\
2a & {$\left[\mathrm{P}_{444} \mathrm{E}_{2}\right] \mathrm{Cl}$} & 321 & 1261 & miscible $^{\mathrm{b}}$ \\
$3 \mathrm{a}$ & {$\left[\mathrm{P}_{444} \mathrm{E}_{3}\right] \mathrm{Cl}$} & 172 & 1259 & miscible $^{\mathrm{b}}$ \\
$1 \mathrm{~b}$ & {$\left[\mathrm{P}_{444} \mathrm{E}_{1}\right][\mathrm{DEHP}]$} & 94 & 811 & LCST $^{\text {L }}$ \\
2b & {$\left[\mathrm{P}_{444} \mathrm{E}_{2}\right][\mathrm{DEHP}]$} & 50 & 858 & LCST \\
$3 \mathrm{~b}$ & {$\left[\mathrm{P}_{444} \mathrm{E}_{3}\right][\mathrm{DEHP}]$} & 86 & 790 & LCST \\
\hline
\end{tabular}

${ }^{a}$ n.d.: not determined. Solid at room temperature, melting point: $31^{\circ} \mathrm{C}$. ${ }^{b}$ Fully miscible with water in the temperature range $0-100{ }^{\circ} \mathrm{C}$

The physical properties of the DEHP ILs are listed in Table 1. A decrease in viscosity with longer oligo ethylene chain is seen for the chloride ILS (see ESI). Introduction of the bis(2-ethylhexyl) phosphate anion lowers the viscosity. Regarding the phase behaviour of the ionic liquids with water, the structure of the ionic liquid plays a crucial role. Most importantly, the anion drastically changes the miscibility of the ionic liquid with water. All synthesised chloride ionic liquids are fully miscible with water, whilst all the synthesised DEHP ionic liquids show LCST phase behaviour. Also, the role of the cation was investigated. The cloud point temperature was determined for the three different etherfunctionalised ILs in a 1:1 wt/wt mixture with water. Complete phase diagrams were constructed via visual observation of the cloud point upon heating the homogeneous mixtures of different compositions (Figure 2). In addition, more accurate but slow transmission measurements were carried out for some of the compounds to verify the visual observations. In this technique, the cloud point temperature was defined as the temperature at which $50 \%$ of the initial transmission is reached. Temperatures found are: $34{ }^{\circ} \mathrm{C}, 38^{\circ} \mathrm{C}$ and $44{ }^{\circ} \mathrm{C}$ for $1: 1 \mathrm{wt} /$ wt binary mixtures with water of $\left[\mathrm{P}_{444} \mathrm{E}_{1}\right][D E H P], \quad\left[\mathrm{P}_{444} \mathrm{E}_{2}\right][D E H P]$ and $\left[\mathrm{P}_{444} \mathrm{E}_{3}\right][D E H P]$, respectively (Figure S1). These temperatures are practical for extraction applications, since increasing the temperature by 10 to $20^{\circ} \mathrm{C}$ above room temperature is sufficient for complete phase separation. The cloud point temperature increases with increasing oligo ethylene chains. This can be explained as follows. Mixing of the IL and water will occur when the Gibbs free energy of mixing $\Delta G_{\text {mix }}$ is negative:

$$
\Delta G_{\text {mix }}=\Delta H_{\text {mix }}-T \Delta S_{\text {mix }}
$$

In case of LCST phase behaviour, $\Delta S_{\text {mix }}$ is negative. Below the LCST, the two components are fully miscible due to the formed hydrogen bonds between water and the IL, resulting in a hydration shell around the ions. With increasing temperature, this hydrogen bonding is more and more lost until eventually all water molecules from the hydration shell are expelled into the bulk water. A longer oligo ethylene chain in the ionic liquid has more possibilities for hydrogen bonds with water; hence a higher temperature is needed to break them up. The lower cloud point temperature of $\left[\mathrm{P}_{4444}\right][\mathrm{DEHP}]$ :water in comparison with $\left[\mathrm{P}_{444} \mathrm{E}_{3}\right][\mathrm{DEHP}]$ :water can be explained in a similar way: $\left[\mathrm{P}_{4444}\right][\mathrm{DEHP}]$ allows for less possible interactions with water, since this IL lacks functional groups (Figure 3).

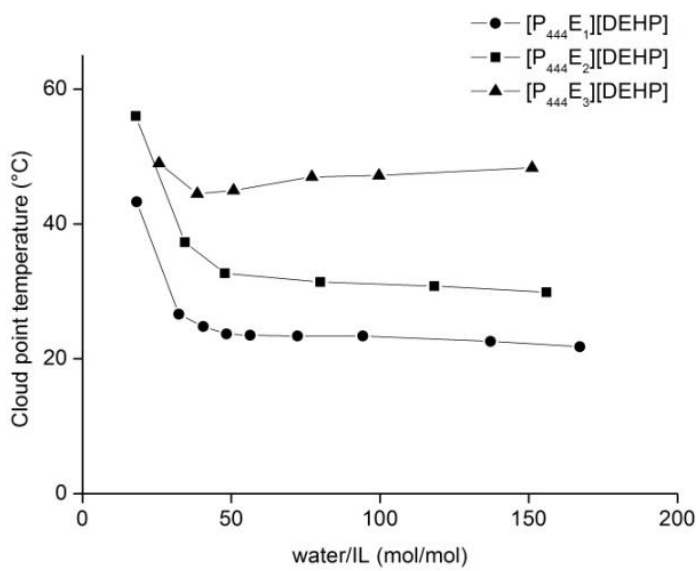

Figure 2. Phase diagrams of the binary mixtures of three ether-functionalised ILs with water.

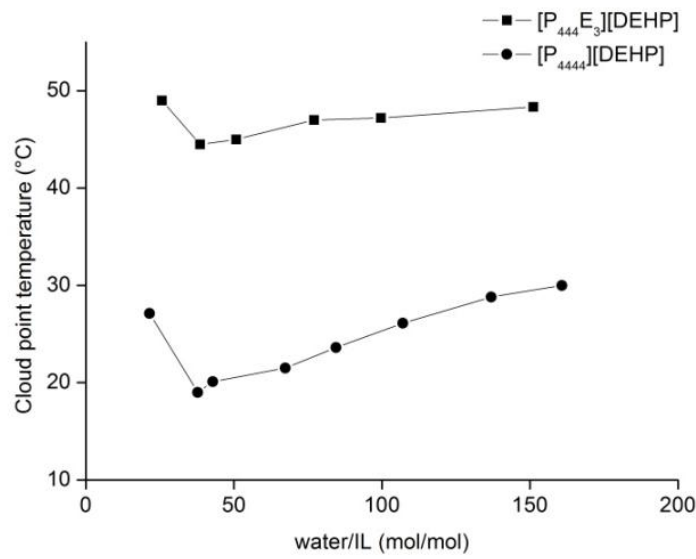

Figure 3. Comparison of cloud point temperatures between functionalised $\left(\left[\mathrm{P}_{444} \mathrm{E}_{3}\right][\mathrm{DEHP}]\right)$ and non-functionalised $\left.\left(\mathrm{P}_{4444}\right][\mathrm{DEHP}]\right)$ ionic liquid.

Bis(2-ethylhexyl)phosphoric acid is a well-known extractant in hydrometallurgical processes for the separation of divalent transition metals. ${ }^{29-31}$ Therefore, the bis(2-ethylhexyl) phosphate ILs were tested for homogeneous liquid-liquid extraction of $3 d$ transition metals. The binary mixture of the ionic liquid $\left[\mathrm{P}_{444} \mathrm{E}_{3}\right][\mathrm{DEHP}]$ and water was used for the extraction of cobalt(II), copper(II), nickel(II) and zinc(II). The original cloud point of the $1: 1 \mathrm{wt} / \mathrm{wt}$ mixture was $44{ }^{\circ} \mathrm{C}$. Yet, the presence of salts in the extraction system influences this cloud point temperature. It is known that the alkaline-earth chloride salts induce a lowering of the lower critical solution temperature. ${ }^{32}$ In this case, with the divalent transition metal ions, the cloud point temperature is reduced significantly. The cloud point temperatures are decreased to approximately $20{ }^{\circ} \mathrm{C}$ for contacting the IL with an aqueous solution of approximately $5000 \mathrm{ppm}$ of the metal. The reduction in temperature is beneficial for homogeneous liquidliquid extraction on a laboratory scale, since the homogeneous region is formed by cooling the mixtures down in an ice bath. However, this lowering of the cloud point temperature can also be disadvantageous since it was observed that no metal concentrations higher than $8000 \mathrm{ppm}$ could be used. The high salt concentration induces a lowering of the cloud point temperature outside the window of cooling by ice water $\left(<0^{\circ} \mathrm{C}\right)$. 
Prior to the homogeneous liquid-liquid extraction experiments, the IL was presaturated with water to minimize phase changes. A 1:1 $\mathrm{wt} / \mathrm{wt}$ binary mixture of the IL and water was made. After homogenisation and subsequent settling of the two phases, it was found that $18 \mathrm{wt} \%$ of water dissolved in the IL phase (Karl Fischer titration) and $6 \mathrm{wt} \%$ of IL was lost into the water layer (quantitative NMR - see ESI). The influence of the extraction time at $0{ }^{\circ} \mathrm{C}$ below LCST on the percentage extraction (\%E) was investigated first (Figure S2). After $5 \mathrm{~min}$, no significant changes in the $\% E$ were observed, so this cooling time was chosen. In order to determine the distribution ratios, four different aqueous solutions of approximately $5000 \mathrm{ppm}$ of the metal $\left(\mathrm{CoCl}_{2}, \mathrm{CuCl}_{2}, \mathrm{NiCl}_{2}\right.$ and $\left.\mathrm{ZnCl}_{2}\right)$ were mixed with the ionic liquid $\left[\mathrm{P}_{444} \mathrm{E}_{3}\right][\mathrm{DEHP}]$ in the homogeneous phase. After settling at room temperature for $10 \mathrm{~min}$ to form the biphasic system again, the mixtures were centrifuged to ensure full phase separation. Then, the aqueous phases were separated and analysed for their metal content by total reflection $\mathrm{X}$-ray fluorescence (TXRF). The distribution ratios were calculated as:

$$
D=\frac{c_{\mathrm{in}}-\mathrm{c}_{\mathrm{aq}}}{c_{\mathrm{aq}}}
$$

where $c_{\text {in }}$ and $c_{a q}$ are the metal concentrations in the initial aqueous phase and the aqueous phase after extraction, respectively. The distribution ratios listed in Table 2 were measured for chloride solutions of the respective metals with initial $\mathrm{pH}$ around 3.5. In Figure 4, the three stages of the extraction are presented for copper(II).
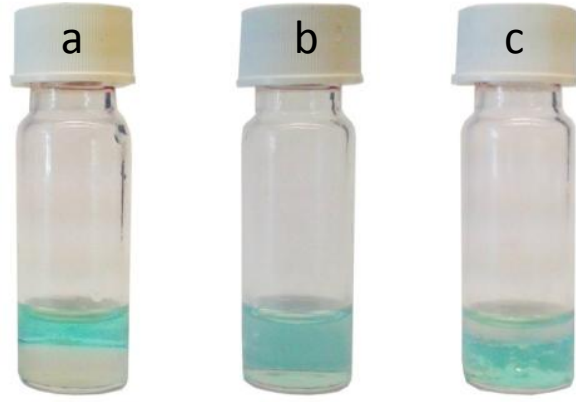

Figure 4. Homogeneous liquid-liquid extraction of $\mathrm{Cu}(\mathrm{II})$ with $\left[\mathrm{P}_{444} \mathrm{E}_{3}\right][\mathrm{DEHP}] / \mathrm{H}_{2} \mathrm{O}$ 1:1 wt/wt mixture (concentration $6866 \mathrm{ppm}$ ) a: initial stage, b: homogeneous phase after $5 \mathrm{~min}$ in ice bath, c: after settling to room temperature. The upper layer is the aqueous phase; the ionic liquid phase is the bottom layer.

In the Irving-Williams series, the general stability sequence of high spin octahedral metal complexes for the replacement of water by other ligands is given as $\mathrm{Co}(\mathrm{II})<\mathrm{Ni}(\mathrm{II})<\mathrm{Cu}(\mathrm{II})>\mathrm{Zn}(\mathrm{II}) .{ }^{33}$ In case of the extraction with the bis(2-ethylhexyl)phosphate anion, the general order is followed, $\mathrm{Co}(\mathrm{II})$ is extracted the least, $\mathrm{Zn}(\mathrm{II})$ is extracted better and $\mathrm{Cu}(\mathrm{II})$ is the metal ion with the highest distribution ratio (Table 2).

Stripping was performed by adding a 1:1 molar ratio of solid oxalic acid to the isolated IL phase. After shaking at $40{ }^{\circ} \mathrm{C}$ for $30 \mathrm{~min}$ at $3000 \mathrm{rpm}$, a sample of the IL phase was analysed with TXRF for its metal content (Table 2). The percentage stripping $\% \mathrm{~S}$ is defined as follows:

$$
\% S=\frac{c_{\text {ILbs }}-c_{\text {ILas }}}{c_{\text {ILbs }}} \times 100 \%
$$

where $c_{\text {ILbs }}$ and $c_{\text {ILas }}$ are the metal concentration of the ionic liquid phase before and after stripping, respectively. This precipitation stripping technique is advantageous since the metal is removed in one single step. Using oxalic acid as stripping agent, almost all $\mathrm{Co}$ (II) and $\mathrm{Ni}(\mathrm{II})$ was precipitated as their respective oxalates. The stripping with oxalic acid was still very efficient for $\mathrm{Zn}$ (II), more than $90 \%$ of the metal was recovered as oxalate. For $\mathrm{Cu}(\mathrm{II})$, the IL solution was still very blue coloured and only $58 \%$ of the metal ion was stripped from the organic phase (Figure S4). Apparently, the most extracted ion, $\mathrm{Cu}(\mathrm{II})$, is also the most difficult to remove from its complex with the addition of oxalic acid. Instead, the stronger acid $\mathrm{H}_{2} \mathrm{SO}_{4}$ was used to strip $\mathrm{Cu}(\mathrm{II}) .500 \mathrm{mg}$ of the loaded IL phase was contacted with $500 \mathrm{mg}$ of a $1 \mathrm{M} \mathrm{H}_{2} \mathrm{SO}_{4}$ solution. A light blue precipitate was formed and a percentage stripping of $99 \%$ was obtained (Table 2).

It must be noted that the IL cannot be used for a new extraction step directly after stripping, since the anion is now protonated and the chloride IL reformed. Simply by a washing step with an alkaline solution, the DEHP IL is fully restored and ready for another extraction/stripping cycle.

Table 2. Extraction of $1^{\text {st }}$ row transition metals (Co(II), Ni(II), $\left.\mathrm{Cu}(\mathrm{II}), \mathrm{Zn}(\mathrm{II})\right)$ with $\left[P_{444} E_{3}\right][D E H P]$, initial metal concentrations in the aqueous phase $\left(c_{i}\right)$ and metal concentration in the aqueous phase after extraction $\left(c_{a q}\right)$, the initial $\mathrm{pH}$ of the solutions, their distribution ratios $D$ and the percentage stripping $\% S$ when contacted with solid oxalic acid (for $\mathrm{Cu}(\mathrm{II})$, also with $\mathrm{H}_{2} \mathrm{SO}_{4}$ ).

\begin{tabular}{cccccc}
\hline $\begin{array}{c}\text { Metal } \\
\text { ion }\end{array}$ & $\mathrm{c}_{\mathrm{i}}$ & $\mathrm{pH}_{\text {in }}$ & $\mathrm{c}_{\mathrm{aq}}$ & $D$ & $\% \mathrm{~S}$ \\
\hline $\mathrm{Co}(\mathrm{II})$ & 6866 & 3.2 & 1278 & 4.4 & 99 \\
$\mathrm{Ni}(\mathrm{II})$ & 5578 & 3.4 & 286 & 19 & 99 \\
$\mathrm{Cu}(\mathrm{II})$ & 4480 & 3.9 & 128 & 34 & $58 / 99$ \\
$\mathrm{Zn}(\mathrm{II})$ & 7466 & 3.0 & 285 & 25 & 91 \\
\hline
\end{tabular}

The coordination of the metal ions by the IL was studied by FTIR spectroscopy. By comparing ATR-FTIR spectra for presaturated IL and the IL loaded with Co(II), an obvious shift to lower wavenumbers was observed for two peaks (Figure S3). The first one: around $1200 \mathrm{~cm}^{-1}$, a small shift in the peak corresponding to a $\mathrm{P}=\mathrm{O}$ stretch, and around $1600 \mathrm{~cm}^{-1}$, a larger shift in the peak corresponding to the $\mathrm{P}^{-} \mathrm{O}^{-}$stretch. $^{34}$ As expected, this indicates the interaction between this functional group and the metal cation in the extraction.

Also, the selectivity towards other metals was investigated. The extraction of $\mathrm{CsCl}$ has a distribution ratio of 4.1, even lower than the worst divalent metal ion tested (Co(II)). Taking into account that indium and some rare earths are listed as critical metals in the EU Report because of their high supply risk, $^{35}$ and therefore, their recycling demand will increase, these elements were chosen for the study of the selectivity. Unfortunately, these elements form a precipitate when contacted with the ionic liquid. This suggests strong complexation with the bis(2-ethylhexyl)phosphate anion. It is known that the di(2-ethylhexyl)phosphoric acid is an excellent extractant for rare-earth elements and indium. ${ }^{36,37}$ Yet, introducing it as an anion in the ionic liquid leads to formation of an insoluble complex, as was confirmed by TXRF measurements. 
In conclusion, we have shown that the introduction of bis(2ethylhexyl)phosphate as anion in oligo ethylene functionalised phosphonium ionic liquids gives ionic liquids with LCST phase behaviour. The cloud point temperature is tuneable by making modifications in the structure of the ionic liquid. Longer oligo ethylene chains induce higher cloud points. Addition of a metal chloride salt significantly lowers the cloud point temperature. The ionic liquid $\left[\mathrm{P}_{444} \mathrm{E}_{3}\right][\mathrm{DEHP}]$ was used in this first example of homogeneous liquid-liquid extraction of metal ions with an LCST thermomorphic system. The extraction capacity towards DEHP ionic liquid is excellent for divalent metal ions.

\section{Experimental section}

The synthesis was executed as follows. First, the acidic form of the phosphate was neutralised by a base, as described in the literature, ${ }^{38}$ by adding a solution of $20 \mathrm{wt} \% \mathrm{NaOH}$ to bis(2ethylhexyl)phosphoric acid in ethanol absolute until a neutral $\mathrm{pH}$ was reached. The solvent was evaporated and the product was dried in a vacuum oven at $60{ }^{\circ} \mathrm{C}$ for $2 \mathrm{~h}$. The phosphate salt $(1 \mathrm{~mol}$ eq) and the chloride ionic liquid ( $1.5 \mathrm{~mol}$ eq) were dissolved in water and stirred overnight. Dichloromethane was added and the product was extracted to the organic phase and washed with water to remove $\mathrm{NaCl}$ and excess IL. The organic phase was isolated and evaporated to yield pure product. Full characterisation can be found in the ESI. In a typical extraction experiment, $500 \mathrm{mg}$ of the presaturated IL is contacted with $500 \mathrm{mg}$ of an aqueous metal solution. The mixtures were cooled in an ice bath for $5 \mathrm{~min}$ to reach the homogeneous region. Next, the mixtures are left to settle at room temperature for $10 \mathrm{~min}$. A sample was taken from the aqueous layer and analysed for its metal content by TXRF. For a typical stripping experiment, to $500 \mathrm{mg}$ of the loaded IL, equimolar amounts of oxalic acid were added and shaken for $30 \mathrm{~min}$ at room temperature.

\section{Acknowledgements}

This research was financially supported by IWT-Flanders (PhD fellowship to DD), the FWO Flanders (research project G.0900.13) and the KU Leuven (projects GOA/13/008 and IOF-KP RARE3). The authors also wish to thank Karel Duerinckx for NMR measurements and Dirk Henot for performing $\mathrm{CHN}$ analyses.

\section{Notes and references}

1 T. Welton, Chem. Rev., 1999, 99, 2071.

2 P. Wasserscheid, W. Keim, Angew. Chem. Int. Ed., 2000, 39, 3772.

3 N. V. Plechkova, K. R. Seddon, Chem. Soc. Rev., 2008, 37, 123.

4 R. D. Rogers, K. R. Seddon, Science, 2003, 302, 792.

5 J. Lachwa, J. Szydlowski, V. Najdanovic-Visak, L. P. N. Rebelo, K. R. Seddon, M. Nunes da Ponte, J. M. S. Esperança, ., H. J. R. Guedes, J. Am. Chem. Soc., 2005, 127, 6542.

6 J. Lachwa, J. Szydlowski, A. Makowska, K. R. Seddon, J. M. S. S. Esperanca, H. J. R. Guedes, L. P. Rebelo, Green Chem., 2006, 8, 262.
7 A. J. L. Costa, M. R. C. Soromenho, K. Shimizu, J. M. S. S. Esperanca, J. N. C. Lopes, L. P. Rebelo, RSC Adv., 2013, 3, 10262.

8 S. Dong, B. Zheng, Y. Yao, C. Han, J. Yuan, M. Antonietti, F. Huang, Adv. Mater., 2013, 25, 6864.

9 Y. Kohno, H. Ohno, Aust. J. Chem., 2012, 65, 91.

10 S. Saita, Y. Kohno, H. Ohno, Chem. Commun., 2013, 49, 93.

11 Y. Kohno, H. Ohno, Chem. Commun., 2012, 48, 7119.

12 Y. Kohno, H. Ohno, Phys. Chem. Chem. Phys., 2012, 14, 5063.

13 Y. Kohno, H. Arai, H. Ohno, Chem. Commun., 2011, 47, 4772.

14 Y. Kohno, H. Arai, S. Saita, H. Ohno, Aust. J. Chem., 2011, 64, 1560.

15 Y. Fukaya, H. Ohno, Phys. Chem. Chem. Phys., 2013, 15, 4066.

16 Y. Fukaya, K. Sekikawa, K. Murata, N. Nakamura, H. Ohno, Chem. Commun., 2007, 3089.

17 K. Fukumoto, H. Ohno, Angew. Chem. Int. Ed., 2007, 46, 1852.

18 P. Nockemann, B. Thijs, S. Pittois, J. Thoen, C. Glorieux, K. Van Hecke, L. Van Meervelt, B. Kirchner, K. Binnemans, J. Phys. Chem. B, 2006, 110, 20978.

19 B. Onghena, K. Binnemans, Ind. Eng. Chem. Res., 2015, 54, 1887.

20 T. Vander Hoogerstraete, B. Onghena, K. Binnemans, J. Phys. Chem. Lett., 2013, 4, 1659.

21 T. Vander Hoogerstraete, B. Onghena, K. Binnemans, Int. J. Mol. Sci., 2013, 14, 21353.

22 B. Onghena, J. Jacobs, L. Van Meervelt, K. Binnemans, Dalton Trans., 2014, 43, 11566.

23 M. Blesic, H. Q. N. Gunaratne, J. Jacquemin, P. Nockemann, S. Olejarz, K. R. Seddon, C. R. Strauss, Green Chem., 2014, 16, 4115.

24 D. Nakayama, Y. Mok, M. Noh, J. Park, S. Kang, Y. Lee, Phys. Chem. Chem. Phys., 2014, 16, 5319.

25 S. Sun, P. Wu, Macromolecules, 2012, 46, 236.

26 Y. Kohno, S. Saita, K. Murata, N. Nakamura, H. Ohno, Polym. Chem., 2011, 2, 862.

27 Y. Ito, Y. Kohno, N. Nakamura, Ohno, Int. J. Mol. Sci., 2013, 14, 18350

28 V. Gudipati, D. P. Curran, C. S. Wilcox, J. Org. Chem., 2006, 71, 3599.

29 Z. J. Yu, T. H. Ibrahim, R. D. Neuman, Solvent Extr. Ion Exc., 1998, 16, 1437.

30 T. C. Huang, R. S. Juang, Ind. Eng. Chem. Fund., 1986, 25, 752.

31 A. Mellah, D. Benachour, Chem. Eng. Process., 2006, 45, 684.

32 D. Dupont, D. Depuydt, K. Binnemans, J. Phys. Chem. B, 2015, 119, 6747

33 H. Irving, R. J. P. Williams, J. Chem. Soc., 1953, 3192.

34 Stuart, B. H., Organic Molecules, in Infrared Spectroscopy: Fundamentals and Applications; John Wiley \& Sons: 2004.

35 Report on Critical Raw Materials for the EU, European Commission, DG Enterprise \& Industry, Brussels, 2014

36 T. Sato, Hydrometallurgy, 1989, 22, 121.

37 T. Sato, K. Sato, Hydrometallurgy, 1992, 30, 367.

38 D. C. Steytler, D. L. Sargeant, G. E. Welsh, B. H. Robinson, R. K. Heenan, Langmuir, 1996, 12, 5312. 